\title{
The Watermelon in Our Native Plant Garden
}

The University of Wisconsin-Madison Arboretum has recently undertaken a challenging project to plant a 5 -acre Wisconsin native plant garden around its newly expanded visitor center. The purpose of this garden is to provide small, visitor-friendly vignettes of the various types of plant communities found throughout the state and the Arboretum. From my office windows, I can see the part of this new garden that has been planted at the entrance to the new addition. It contains columbine, spiderwort, sedges, blue-eyed grass, bee balm, a young Juneberry, and an aspen grove. Throughout the summer I noticed visitors enjoying the blooms of these plants from the elevation of the entrance stairway. More recently, however, their attention focused on a corner of the garden where I thought nothing had been planted. So what was the new attraction? To satisfy my curiosity I went outside to look. To my surprise, the center of attention turned out to be a single, vigorous watermelon plant-an uninvited interloper in our native plant garden.

Now, our gardener, Susan Carpenter, and her crew take great care to remove all the weeds in this garden, but they decided to leave the watermelon alone. I think this was a wise choice and here's why: Watermelon (Citrullus lanatus var. lanatus) is a plant of African origin that Spanish explorers brought to the Americas by the mid-1500s. Being gardeners, many Native American tribes, including the Cherokee, Seminole, Iroquois, Chickasaw, Cheyenne, Kiowa, Rappahannock, Cahuilla, Cocopa, Havasupai, Hopi, Kamia, Navajo/Diné, Meswaki, Okanagan-Colville, Pima and Sia, quickly recognized the value of watermelon as a foodstuff and the medicinal properties of watermelon seeds. They began growing watermelons and soon were cultivating new varieties adapted to the environmental conditions of their particular region. Thus the watermelon, unlikely as it may seem to most of us, has a long cultural heritage in North America-one that began, as did the peach (Prunus persica) and the horse (Equus caballus), during the era of European exploration, but before that of extensive European settlement. These species are, of course, part of what historian Alfred Crosby calls the "Columbian exchange," which involved the transfer of species across the Atlantic in both directions after 1492. They also represent that shadowy zone of useful naturalized species that in some respects we might consider native or tended "wild" species, as does Gary Paul Nabhan, the eminent ethnobotanist of the American
Southwest. These species, like ecological restoration, exist at the intersection of nature and culture, and because they do, they provide us with yet one more means of interpreting our complicated, but common, history.

The watermelon in the native plant garden also suggests a need to re-examine our restoration goals. Like our native plant garden at the Arboretum, I would argue that ecological restorations in North America, Europe, and Australia rarely have as one of their goals the consumptive use of the plants or animals restored. Well, all right, those projects that restore habitat for hunting waterfowl or catching fish have this in mind, but plantoriented restorationists rarely see the possibility of even making tea from ubiquitous and easy-to-grow plants, such as bee balm, wild strawberry, or wild roses. Why not? Why not harvest some of the willows growing in the middle of Curtis Prairie for basket materials or other uses? Why not use wooden or even high-tech digging sticks to dig the edible bulbs of spring beauty or one of the many species of Erythronium? What would it hurt to collect acorns, mesquite pods, serviceberries, camas, or purple poppy mallow to eat? It's not uncommon to enjoy Native American foods, such as maple syrup, wild rice, blueberries and cranberries, so why not some of these wild plants? Perhaps by our collecting we might help to spread or invigorate these species as the Native Americans did.

Now, I'm not suggesting that collecting plants for food or other uses should be done in any way that compromises the plant populations of extant or restored plant communities. Like overcollecting seeds for planting purposes, we have to recognize that we must limit our desires and activities. But with this ethical standard in mind and after experimenting to determine the interactions of collecting and plant population dynamics, why not eat or otherwise use at least some of the fruits of our labors and share them with others? This, it seems to me, is another way that ecological restoration can foster a closer bond between people and their environment, and may serve as first step toward understanding the real day-to-day issues of sustainability in our lives and the lives other human beings around the world.

$\mathrm{Oh}$, about the watermelons in our native plant garden. They were delicious!

Dave Egan 